\title{
Influence of Donor C3 Allotype on Late Renal-Transplantation Outcome
}

\author{
Katherine M. Brown, M.Sc., Elli Kondeatis, M.D., Ph.D., Robert W. Vaughan, Ph.D., \\ Sui P. Kon, M.D., Ph.D., Christopher K.T. Farmer, M.D., John D. Taylor, M.D., \\ Xiang He, Ph.D., Atholl Johnston, Ph.D., Catherine Horsfield, M.R.C.Path., \\ Bert J.C. Janssen, M.Sc., Piet Gros, Ph.D., Wuding Zhou, M.D., Ph.D., \\ Steven H. Sacks, M.D., Ph.D., and Neil S. Sheerin, M.D., Ph.D.
}

ABSTRACT

From the Department of Nephrology and Transplantation, King's College London, Guy's Hospital, London (K.M.B., J.D.T., W.Z. S.H.S., N.S.S.); the Clinical Transplantation Laboratories, Guy's Hospital, London (E.K., R.W.V.); King's College Hospital, London (S.P.K.); Kent and Canterbury Hospital Canterbury, United Kingdom (C.K.T.F.); the Department of Clinical Pharmacology, Barts and the London, Queen Mary's School of Medicine and Dentistry, London (X.H., A.J.) the Department of Histopathology, Guy's and St. Thomas' National Health Service Foundation Trust, London (C.H.); and the Department of Crystal and Structural Chemistry, Bijvoet Center for Biomolecular Research, Faculty of Science, Utrecht University, Utrecht, the Netherlands (B.J.C.J., P.G.) Address reprint requests to Dr. Sheerin at the Department of Nephrology and Transplantation, 5th Fl., Thomas Guy House Guy's Hospital, London SEl 9RT, United Kingdom, or at neil.sheerin@kcl.ac.uk.

N EnglJ Med 2006;354:2014-23.

Copyright () 2006 Massachusetts Medical Society.

\section{BACKGROUND}

The complement system has a critical role in both the innate and the adaptive immune responses. In humans, C3 exists as two main allotypes, $\mathrm{F}$ (fast) and S (slow), which are known to affect the incidence of inflammatory disease. We conducted a study to address the influence of these alleles on late renal-graft outcome.

\section{METHODS}

We determined the $\mathrm{C} 3$ allotypes of 662 pairs of adult kidney donors and recipients from 1993 through 2002 and then related C3F/S polymorphism status to demographic and clinical outcome data. The median length of follow-up was 3.3 years.

RESULTS

Analysis of 513 pairs of white donors and recipients identified $113 \mathrm{C} 3 \mathrm{~S} / \mathrm{S}$ recipients of a C3S/F or a C3F/F kidney and $179 \mathrm{C} 3 \mathrm{~S} / \mathrm{S}$ recipients of a C3S/S kidney. Graft survival was significantly better with a C3F/F or C3F/S donor allotype than a C3S/S allotype $(\mathrm{P}=0.05)$. The hazard ratio for graft loss of $\mathrm{C} 3 \mathrm{~S} / \mathrm{S}$ kidneys, as compared with $\mathrm{C} 3 \mathrm{~F} / \mathrm{F}$ or $\mathrm{C} 3 \mathrm{~F} / \mathrm{S}$ kidneys, was 2.21 (95 percent confidence interval, 1.04 to $4.72 ; \mathrm{P}=0.04$ ). The graft function of $\mathrm{C} 3 \mathrm{~F} / \mathrm{F}$ or $\mathrm{C} 3 \mathrm{~F} / \mathrm{S}$ donor kidneys was significantly better than that of $\mathrm{C} 3 \mathrm{~S} / \mathrm{S}$ donor kidneys $(\mathrm{P}<0.001)$. The effect of the $\mathrm{C} 3 \mathrm{~F}$ allele was specific to recipients who did not themselves possess this allele. Multivariate analysis excluded effects of other factors known to influence graft outcome.

\section{CONCLUSIONS}

Expression of $\mathrm{C} 3$ alleles by donor renal cells appears to have a differential effect on late graft outcome. Among white C3S/S recipients, receipt of a C3F/F or C3F/S donor kidney, rather than a C3S/S donor kidney, is associated with a significantly better long-term outcome. These findings suggest that the two alleles have functional differences. 
$\mathrm{D}$ ESPITE IMPORTANT ADVANCES IN THE use of immunosuppressive therapy to reduce renal allograft loss resulting from acute rejection, the long-term rate of renal allograft survival has remained static, with only 54.4 percent of kidneys from living donors and 36.4 percent of kidneys from deceased donors functioning 10 years after transplantation. ${ }^{1}$ Chronic allograft nephropathy, which is multifactorial in origin, remains the leading cause of allograft loss after the first year. ${ }^{2}$

The complement system consists of a set of proteins that, when activated, generate important effectors of the innate and adaptive immune responses. The complement system may be activated at several stages during renal transplantation and can contribute to tissue injury that may influence the long-term outcome of the allograft. ${ }^{3}$ Three pathways of complement activation proceed through the cleavage of $\mathrm{C} 3$, the most abundant and functionally diverse complement component. ${ }^{4,5}$

The renal tubular epithelium is both an important extrahepatic source of $\mathrm{C} 3$ and a major target of immunologic injury during rejection. ${ }^{6,7}$ The donor kidney contributes 5 percent of the total circulating C3 pool when it is in its stable state but up to 16 percent during acute rejection. The functional importance of local C3 synthesis in renal transplantation has been demonstrated in a mouse model of acute rejection. ${ }^{8}$

Human C3 exists as two common allotypic variants, designated C3F (fast) and C3S (slow) on the basis of electrophoretic motility. ${ }^{9}$ At the molecular level, there is a single-nucleotide substitution (C to $\mathrm{G}$ ) and consequent amino acid substitution ${ }^{10}$ that can be characterized by amplification refractory mutation system analysis. ${ }^{11}$ The C3F allele is the less common variant; it is present in highest frequency in white populations (20 percent). Only 5 percent of blacks and 1 percent of Asians have the $\mathrm{C} 3 \mathrm{~F}$ allele. ${ }^{12}$ In disease-association studies, an increased prevalence of the $\mathrm{C} 3 \mathrm{~F}$ allotype has been linked to a number of immunemediated diseases, such as IgA nephropathy, ${ }^{13}$ systemic vasculitis, ${ }^{14}$ and mesangiocapillary glomerulonephritis. ${ }^{15,16}$

In a study of renal-transplant recipients, the C3F polymorphism was not associated with an increased likelihood of first-year graft loss, although its presence in either donor or recipient increased the risk of early graft dysfunction, with a higher serum creatinine level at one year in re- cipients with the polymorphism than in those without it. ${ }^{17}$ We determined whether the presence of C3 polymorphisms influenced the long-term outcome of grafts.

\section{METHODS}

\section{STUDY POPULATION}

Between January 1993 and September 2002, 949 adults underwent renal transplantation at Guy's and St. Thomas' National Health Service Foundation Trust in London. DNA was available for C3 allotyping from 662 pairs of donors and recipients (Fig. 1). The study design was approved by the research ethics committee of Guy's Hospital. Patients were not required to give consent, since their anonymity was maintained. The authors were responsible for the study design, data collection and analysis, and manuscript preparation.

The following clinical data were obtained for all patients: age, sex, number of HLA mismatches, race (of recipient only, as designated by investigators), blood group, number of previous kidney transplants, cause of end-stage renal disease, duration of cold ischemia, the presence or absence of delayed graft function, results of panel-reactive antibody testing (values before transplantation and peak values), type of donor (cadaveric, living related, or living unrelated), status of allograft (functioning in living patient, functioning at the time of patient's death, or nonfunctioning), cause of allograft loss, and vital status (with the cause of death determined in patients who died). Chronic allograft nephropathy was defined as progressive renal dysfunction accompanied by glomerulosclerosis, tubular atrophy, chronic interstitial fibrosis, and vascular occlusive changes. ${ }^{18}$

For patients who continued to be followed at Guy's Hospital, the following data were also collected: the number of episodes of rejection, the histologic severity of rejection, ${ }^{19}$ the type of immunosuppressive therapy (at induction, three months, and one, three, and five years), the use of polyclonal antibodies, and discontinuation of corticosteroids. Twenty-nine patients (of whom 23 were white) with primary nonfunction of the graft, defined by the lack of a physiologically important decline in serum creatinine levels or the continued need for dialysis, were excluded from subsequent analyses. Data on patients who died with a functioning allograft were also censored at the time of death.

The glomerular filtration rate was estimated by means of the abbreviated Modification of Diet 


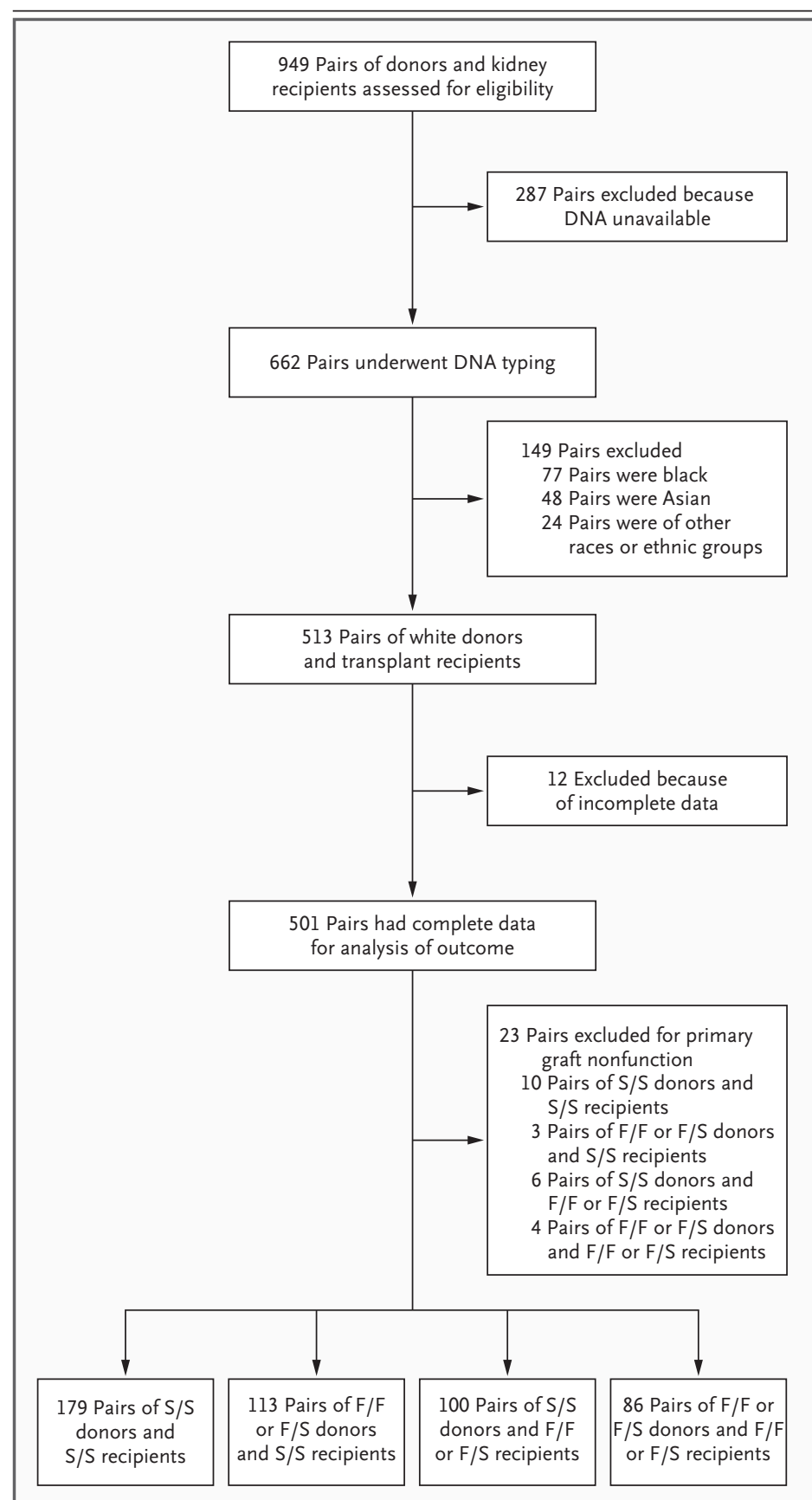

Figure 1. Kidney-Transplant Recipients Eligible for Study Inclusion, DNA Allotyping, and Clinical Outcome Data.

in Renal Disease equation, which is based on serum creatinine level, age, sex, and race. ${ }^{20}$ Serum creatinine levels six months after transplantation and yearly thereafter were calculated as the mean of the three creatinine measurements obtained closest to each interval.
AMPLIFICATION REFRACTORY MUTATION SYSTEMS ANALYSIS FOR C3 ALLOTYPING

Genomic DNA was extracted from peripheralblood samples from graft recipients and living donors and from spleen cells from cadaveric donors ${ }^{21}$ and stored at $-20^{\circ} \mathrm{C}$ until analyzed. Twentyone oligonucleotide primers were based on and validated against previously used primer sequences and accurately identified the C3 allotype in DNA from persons whose allotype was known (for details see the Supplementary Appendix, available with the full text of this article at www.nejm.org). Paired polymerase-chain-reaction (PCR) assays were performed for each donor and recipient; both reactions contained a common antisense primer and one allele-specific sense primer. The $3^{\prime}$ base on the sense primers was complementary to the nucleotide substitution that defined the F or S allele. The primers amplified a 278 -bp region. ${ }^{16}$ The sense primer sequence was 5 'AGTTCAAGTCAGAAAAGGTGG3' for C3F and 5'AGTTCAAGTCAGAAAAGGTGC3' for C3S. The common antisense primer sequence was 5'CGTCCGGCCCACGGGTA3'.

PCR was performed in a Perkin-Elmer DNA Thermal Cycler with $0.2 \mu \mathrm{g}$ of genomic DNA. The PCR conditions were as follows: initial denaturation at $94^{\circ} \mathrm{C}$ for 1 minute; five cycles of denaturing at $94^{\circ} \mathrm{C}$ for 25 seconds, annealing at $70^{\circ} \mathrm{C}$ for 45 seconds, and extension at $72^{\circ} \mathrm{C}$ for 30 seconds; 20 cycles at $94^{\circ} \mathrm{C}$ for 25 seconds, $63^{\circ} \mathrm{C}$ for 45 seconds, and $72^{\circ} \mathrm{C}$ for 30 seconds; and five cycles at $94^{\circ} \mathrm{C}$ for 25 seconds, $55^{\circ} \mathrm{C}$ for 1 minute, and $72^{\circ} \mathrm{C}$ for 2 minutes.

Each PCR run also included reactions containing DNA samples of a known C3 allotype, ${ }^{16}$ as well as reactions containing no DNA, to control for contamination. Control primers (5'TGCCAAGTGGAGCACCCAA3') and (5'GCATCTTGCTCTGTGCAGAT3'), which amplified a highly conserved DNA fragment of $750 \mathrm{bp}$, were added to each reaction. The amplification products were then subjected to electrophoresis on 1 percent $(w t / v o l)$ agarose gel. Two operators independently evaluated the result for each subject, and a $\mathrm{C} 3$ allotype was assigned only when the two reached a consensus.

\section{STATISTICAL ANALYSIS}

The relation of the $\mathrm{C} 3$ allele to allograft survival was examined by means of the log-rank test, and its relation to function was evaluated by two-group 
repeated-measures analysis of variance. Continuous variables were compared with the use of a two-tailed unpaired t-test for the mean categorical variables with the use of the chi-square test, and ordinal variables with the use of the Wilcoxon-Mann-Whitney test. A P value of less than 0.05 was considered to indicate statistical significance; all $\mathrm{P}$ values were two-sided. A stepwise stratified Cox model was used for multivariate analyses to identify independent risk factors for long-term graft loss.

\section{RESULTS}

Among the 662 donor-recipient pairs who underwent DNA typing, DNA results and complete outcome data were available for 501 pairs of white donors and renal-transplant recipients (Fig. 1). The median duration of follow-up for these patients was 3.3 years (range, 4 days to 10.1 years). In both donors and recipients, the C3S allele frequency was 0.77 and the C3F allele frequency was 0.23 . These results were consistent with their known frequencies in white populations and were in Hardy-Weinberg equilibrium. The primary rate of nonfunction (defined as the lack of function of the allograft from the time of transplantation) was similar in all groups.

The patients were divided into four groups according to the presence or absence of the C3F allele in the donor and the recipient (Fig. 1). Kaplan-Meier estimates of graft survival are shown in Figure 2A. Among C3S/S recipients, the presence of one or two donor C3F alleles was associated with a higher rate of graft survival than was the presence of two C3S alleles ( $\mathrm{P}=0.05$ by the log-rank test). The median follow-up time was similar among $\mathrm{C} 3 \mathrm{~S} / \mathrm{S}$ recipients of $\mathrm{C} 3 \mathrm{~F} / \mathrm{F}$ or $\mathrm{C} 3 \mathrm{~F} / \mathrm{S}$ kidneys and $\mathrm{C} 3 \mathrm{~S} / \mathrm{S}$ recipients of $\mathrm{C} 3 \mathrm{~S} / \mathrm{S}$ kidneys (3.6 and 3.2 years, respectively). During the first year after transplantation, there was no significant difference in allograft survival between the two groups (data not shown), a result consistent with that of a previous study. ${ }^{17}$ However, the survival curves diverged after one year, and at eight years, the rate of graft survival was 36.1 percent higher among C3S/S recipients of one or two donor $\mathrm{C} 3 \mathrm{~F}$ alleles than among C3S/S recipients of two donor $\mathrm{C} 3 \mathrm{~S}$ alleles $(\mathrm{P}=0.01$ by the log-rank test with year 1 allograft losses excluded). The better outcome among C3S/S patients receiving a $\mathrm{C} 3 \mathrm{~F} / \mathrm{F}$ or $\mathrm{C} 3 \mathrm{~F} / \mathrm{S}$ kidney was accounted for by the smaller number of allograft losses attributed to chronic allograft nephropathy $(\mathrm{P}=0.009)$ (Table 1$)$. The allograft survival advantage associated with the C3F donor allele was not seen when recipients themselves were heterozygous or homozygous for a C3F allele. We were unable to assess whether there was a dose effect of the C3F allele, since only 13 donors who were homozygous for the $\mathrm{C} 3 \mathrm{~F}$ allele were identified. The effect of the $\mathrm{C} 3 \mathrm{~F}$ allele was not observed in nonwhite transplant recipients (data not shown), although numbers were too small to exclude an effect.

Demographic and clinical characteristics of donors and recipients that are known to influence long-term allograft outcome among recipients of a C3S/S kidney or a kidney with one or two C3F alleles are listed in Table 1 . There were no significant differences between the two groups in age, sex, number of HLA mismatches, number of previous transplantations (Table 1), or panel reactive antibody results before transplantation or at peak levels (data not shown). The proportion of transplants from living donors was higher among $\mathrm{C} 3 \mathrm{~S} / \mathrm{S}$ recipients of $\mathrm{C} 3 \mathrm{~S} / \mathrm{S}$ grafts than among C3S/S recipients of other types of grafts. The difference did not achieve statistical significance $(P=0.06)$, but the direction of this difference would be expected to lessen any beneficial effect related to the presence of $\mathrm{C} 3 \mathrm{~F}$ in the donor kidney. This effect is clearly demonstrated by the greater effect of the C3F allele than of the C3S allele among $\mathrm{C} 3 \mathrm{~S} / \mathrm{S}$ recipients of cadaveric kidneys $(\mathrm{P}=0.02)$ (Fig. 2B). No effect of the C3F or C3S allele was seen when the outcomes were compared among recipients of kidneys from live donors; however, the absence of effect may reflect insufficient statistical power, since the numbers of patients in these groups were small.

All patients started standard triple immunosuppressive therapy with cyclosporine, azathioprine, and prednisone, and adjustments were made by the attending physician depending on events after transplantation. The types of immunosuppressive therapy were similar at three months (Table 1) and at one, three, and five years after transplantation in the two groups. There were no significant differences in the rate of corticosteroid withdrawal or use of polyclonal antibody at induction. The mean duration of cold ischemia was shorter by approximately 4.5 hours among the $\mathrm{C} 3 \mathrm{~S} / \mathrm{S}$ recipients of a C3S/S kidney than among the $\mathrm{C} 3 \mathrm{~S} / \mathrm{S}$ recipients of a $\mathrm{C} 3 \mathrm{~F} / \mathrm{F}$ or $\mathrm{C} 3 \mathrm{~F} / \mathrm{S}$ kidney. 
The functional effect of this difference is unclear, but the difference would favor the $\mathrm{C} 3 \mathrm{~S} / \mathrm{S}$ recipients of a C3S/S kidney. The rate of immediate allograft function was similar in the two groups, suggesting that the $\mathrm{C} 3 \mathrm{~F} / \mathrm{S}$ polymorphism does not have a major influence on the likelihood of ischemia reperfusion injury. There is published evidence that the $\mathrm{C} 3 \mathrm{~F}$ allele can predispose patients to glomerulonephritis. ${ }^{13,14}$ There was no evidence of an increased rate of recurrent or new glomerular disease among recipients of a kidney from a C3F donor.

The number and severity of episodes of rejection were also similar in the two groups. Biopsy specimens with histologic evidence of acute rejection (Banff grade IA or IB, defined as acute rejection with substantial interstitial infiltration and moderate [IA] or severe [IB] tubulitis) were stained for complement deposition. ${ }^{19} \mathrm{C} 3$ staining was seen focally along the tubular basement membrane and in some glomeruli (with a mesangial and capillary-wall distribution). The localization and intensity of the $\mathrm{C} 3$ staining were independent of the donor C3 allotype. C4d staining was not seen.

The estimated glomerular filtration rate, an indicator of post-transplantation renal function, is shown in Figure 2C. The presence of the C3F allele in the graft was associated with superior allograft function $(\mathrm{P}<0.001$ by two-way analysis of variance). At five years, the estimated glomerular filtration rate in the two groups differed by 9.7 $\mathrm{ml}$ per minute per $1.73 \mathrm{~m}^{2}$ of body-surface area.

Multivariate analysis of the baseline characteristics of donors and recipients with the use of a stepwise stratified Cox model (Table 2) demonstrated that, unsurprisingly, receipt of a cadaveric graft, as opposed to an allograft from a live donor, was predictive of a poorer allograft outcome, with a hazard ratio for graft loss of 16.30 . In addition, receiving a C3S/S kidney, as compared with a kidney with a C3F allele, was predictive of a poorer graft outcome, with a hazard ratio of 2.21 .

\section{DISCUSSION}

Our results demonstrate that the presence of the C3F allele in the donor kidney is beneficial in white transplant recipients. This effect is specific to transplant recipients who do not themselves possess the $\mathrm{C} 3 \mathrm{~F}$ allele. In this group of patients,
Figure 2 (facing page). Kaplan-Meier Estimates of Graft Survival (Panel A), Survival among Recipients of Cadaveric Transplants (Panel B), and Estimated Mean $( \pm S E)$ Glomerular Filtration Rate among Kidney-Transplant Recipients (Panel C), According to the Presence or Absence of the C3F Allele in the Donor and the Recipient. Data on patients who died with functioning grafts were censored at the time of death. Patients with primary nonfunction of the graft were not included in the analysis. In Panels A and B, P values are for the comparison with donor-recipient pairs homozygous for C3S. In Panel C, glomerular filtration rates were estimated by means of the abbreviated Modification of Diet in Renal Disease equation.

graft survival was significantly prolonged, fewer graft losses were attributed to chronic allograft nephropathy, and renal function (as indicated by the glomerular filtration rate) was improved. This result not only provides support for the theory that complement proteins play a key role in allograft dysfunction but also highlights how genetic polymorphisms within the donor kidney may affect graft outcome.

There is increasing awareness of the potential deleterious effects of complement activation in renal-transplant recipients. Complement is activated during graft reperfusion and, in experimental models, clearly contributes to reperfusion injury. ${ }^{22}$ However, in our series, the rate of delayed graft function was not influenced by the $\mathrm{C} 3 \mathrm{~F} / \mathrm{S}$ polymorphism. The deposition of C4d in renal allografts, as detected by immunochemical testing, is indicative of a humoral response against the graft and is seen in severe forms of acute rejection ${ }^{23}$ and in cases of progressive graft dysfunction. ${ }^{24}$ The kidney itself can be an important source of complement proteins: a single transplanted kidney produces 5 percent of the circulating pool of C3 one year after transplantation. ${ }^{6}$ This contribution increases further during renal inflammation. ${ }^{6}$ The local production of complement within the kidney is of functional importance. In mice, allografts that do not produce $\mathrm{C} 3$ survive at least five times as long as allografts that produce $\mathrm{C} 3 .{ }^{8}$ It is likely that local intrarenal C3 production and activation augment the immune response against the allograft, leading to more rapid rejection. . $^{6,25,26}$ Both donor-derived antigen-presenting cells and epithelial cells can produce $\mathrm{C} 3$, and this property can enhance their capacity for immune stimulation. ${ }^{27,28}$ The effect of the C3F or C3S status of the donor on graft survival could be explained by any 


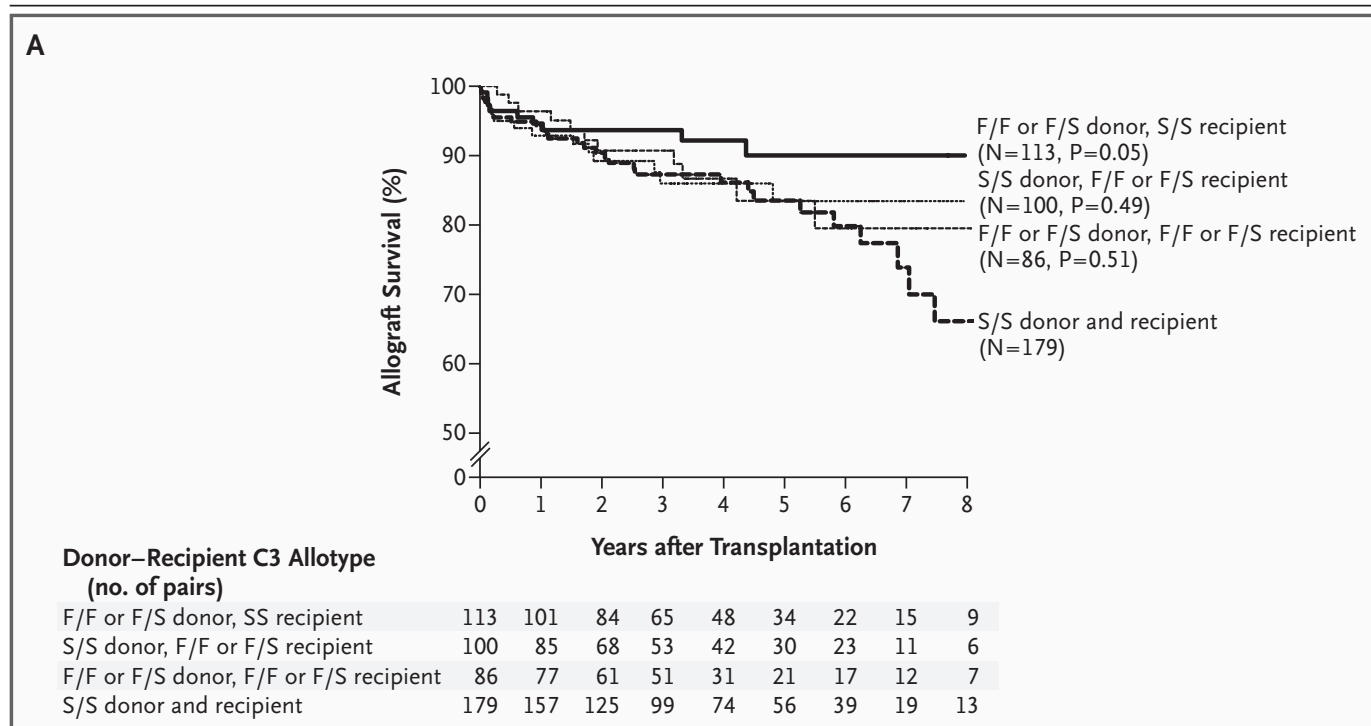

B

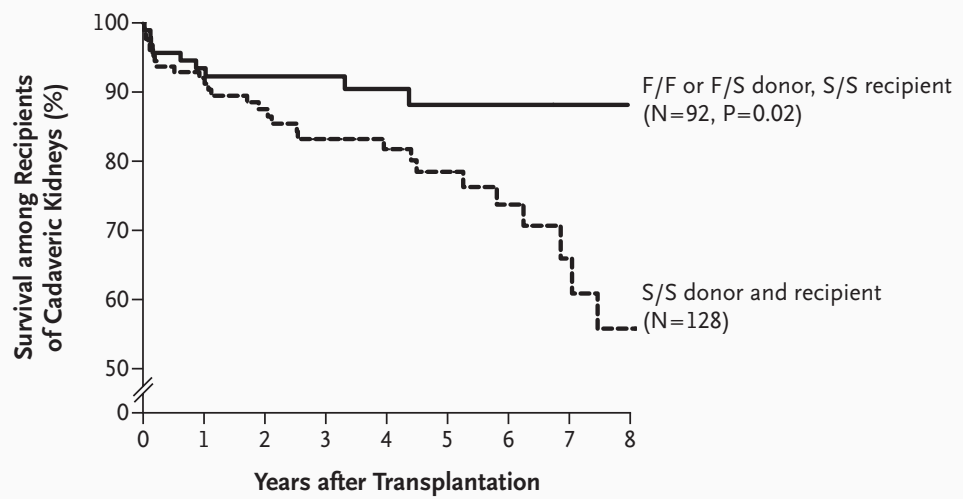

Donor-Recipient C3 Allotype

(no. of pairs)

$\begin{array}{llllllllll}\text { F/F or F/S donor, S/S recipient } & 92 & 81 & 67 & 53 & 42 & 32 & 21 & 14 & 8\end{array}$

$\begin{array}{llllllllll}\mathrm{S} / \mathrm{S} \text { donor and recipient } & 128 & 109 & 85 & 69 & 56 & 40 & 28 & 13 & 10\end{array}$

C

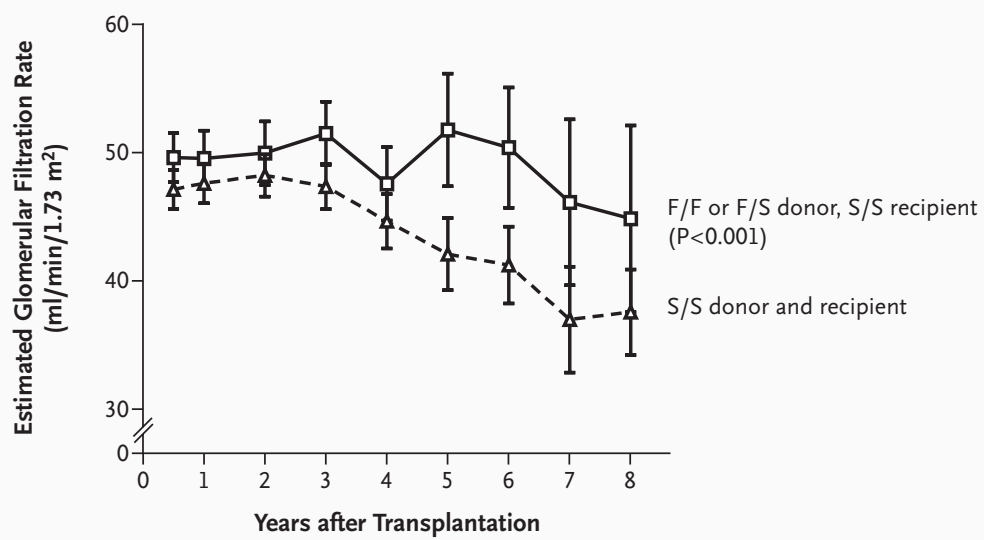

Donor-Recipient C3 Allotype

(no. of pairs)

$\begin{array}{lllllllllll}\text { F/F or F/S donor, S/S recipient } & 63 & 91 & 73 & 58 & 46 & 32 & 18 & 12 & 8\end{array}$

$\begin{array}{llllllllll}\text { S/S donor and recipient } & 100 & 136 & 133 & 90 & 76 & 49 & 34 & 23 & 12\end{array}$ 


\begin{tabular}{|c|c|c|c|}
\hline Characteristic & $\begin{array}{c}\text { C3F/F or C3F/S Donor, } \\
\text { C3S/S Recipient } \\
\text { (N=113) }\end{array}$ & $\begin{array}{l}\text { C3S/S Donor, } \\
\text { C3S/S Recipient } \\
\text { (N=179) }\end{array}$ & P Value \\
\hline Donor age - yr & $40 \pm 16$ & $43 \pm 16$ & 0.19 \\
\hline Recipient age - yr & $42 \pm 15$ & $42 \pm 15$ & 0.98 \\
\hline \multicolumn{4}{|l|}{ Sex of donor - no. } \\
\hline Male & 65 & 93 & 0.35 \\
\hline Female & 48 & 86 & \\
\hline \multicolumn{4}{|l|}{ Sex of recipient - no. } \\
\hline Male & 69 & 114 & 0.65 \\
\hline Female & 44 & 65 & \\
\hline Total HLA mismatches per patient — no. & 2.38 & 2.30 & 0.60 \\
\hline HLA DR mismatches per patient — no. & 0.51 & 0.58 & 0.36 \\
\hline \multicolumn{4}{|l|}{ Donor - no. } \\
\hline Living & 21 & 51 & 0.06 \\
\hline Cadaveric & 92 & 128 & \\
\hline First kidney transplant — \% & 87.6 & 83.2 & 0.31 \\
\hline Steroid withdrawal — \% & 15.4 & 15.9 & 0.93 \\
\hline Antilymphocyte globulin induction — \% & 25.0 & 28.4 & 0.60 \\
\hline Immediate graft function — \% & 75.5 & 83.8 & 0.10 \\
\hline Duration of cold ischemia - $\mathrm{hr}$ & $16.6 \pm 11.1$ & $12.1 \pm 10.6$ & 0.003 \\
\hline \multicolumn{4}{|l|}{ Acute rejection episodes - no. $(\%) \dagger$} \\
\hline Banff grade IA or IB & $25(22.1)$ & $30(16.8)$ & 0.25 \\
\hline Banff grade IIA, IIB, or III & $7(6.2)$ & $6(3.4)$ & 0.25 \\
\hline $\begin{array}{l}\text { Estimated glomerular filtration rate at } 1 \mathrm{yr}- \\
\mathrm{ml} / \mathrm{min} / 1.73 \mathrm{~m}^{2}\end{array}$ & 51.0 & 47.6 & 0.20 \\
\hline Serum creatinine at $1 \mathrm{yr}-\mathrm{mg} / \mathrm{dl}+$ & 1.66 & 1.83 & 0.15 \\
\hline \multicolumn{4}{|l|}{ Cause of end-stage renal failure - no. (\%) } \\
\hline Unknown & $24(21.2)$ & $41(22.9)$ & 0.74 \\
\hline Glomerulonephritis & $33(29.2)$ & $58(32.4)$ & 0.57 \\
\hline Pyelonephritis or reflux nephropathy & $14(12.4)$ & $23(12.8)$ & 0.91 \\
\hline Diabetes & 0 & $5(2.8)$ & 0.07 \\
\hline Renovascular disease or hypertension & $7(6.2)$ & $4(2.2)$ & 0.08 \\
\hline Adult polycystic kidney disease or other disease $\mathbb{}$ & $35(31.0)$ & $48(26.8)$ & 0.44 \\
\hline \multicolumn{4}{|l|}{ Cause of allograft loss - no. (\%) } \\
\hline Chronic allograft nephropathy & $1(0.9)$ & $14(7.8)$ & 0.009 \\
\hline T-cell-or antibody-mediated rejection & $4(3.5)$ & $8(4.5)$ & 0.70 \\
\hline Recurrent or new disease & $2(1.8)$ & $2(1.1)$ & 0.64 \\
\hline Vascular (arterial or venous) thrombosis & $2(1.8)$ & $5(2.8)$ & 0.58 \\
\hline
\end{tabular}

of these antigen-dependent and antigen-indepen- functional importance but also suggest that the dent effects attributable to local production of $\mathrm{C} 3$. effect is allele specific. Either the presence of one

Our data not only provide support for the hy- or more C3F genes or the absence of one or more pothesis that renal allograft $\mathrm{C} 3$ production is of $\mathrm{C} 3 \mathrm{~S}$ genes in the renal allograft is beneficial for 


\begin{tabular}{|c|c|c|c|}
\hline Characteristic & $\begin{array}{c}\text { C3F/F or C3F/S Donor, } \\
\text { C3S/S Recipient } \\
(\mathrm{N}=113)\end{array}$ & $\begin{array}{l}\text { C3S/S Donor, } \\
\text { C3S/S Recipient } \\
\text { (N=179) }\end{array}$ & P Value \\
\hline Immunosuppressive therapy at 3 mo - no.|| & & & 0.73 \\
\hline Cyclosporine and azathioprine & 0 & 1 & \\
\hline Cyclosporine, mycophenolate, and prednisone & 4 & 3 & \\
\hline Cyclosporine and prednisone & 5 & 9 & \\
\hline Cyclosporine, prednisolone, and sirolimus & 42 & 49 & \\
\hline Cyclosporine, prednisone, and sirolimus & 2 & 5 & \\
\hline Tacrolimus, prednisone, and azathioprine & 19 & 18 & \\
\hline Prednisone and mycophenolate & 0 & 3 & \\
\hline Sirolimus, mycophenolate, and prednisone & 1 & 3 & \\
\hline Sirolimus and prednisone & 0 & 2 & \\
\hline Tacrolimus, mycophenolate, and prednisone & 4 & 10 & \\
\hline Tacrolimus and prednisone & 6 & 9 & \\
\hline
\end{tabular}

* The data are shown for all white patients analyzed in the study. Plus-minus values are means \pm SD.

$\uparrow$ Banff grade IA is characterized by acute rejection with substantial interstitial infiltration and moderate tubulitis; grade IB by acute rejection with substantial interstitial infiltration and severe tubulitis; grade IIA by acute rejection with mild to-moderate intimal arteritis; grade IIB by acute rejection with severe intimal arteritis; and grade III by acute rejection with transmural arteritis or arterial fibrinoid change and necrosis of medial smooth-muscle cells, with accompanying lymphocytic inflammation. ${ }^{19}$

To convert values for creatinine to micromoles per liter, multiply by 88.4 .

$\int$ Other diseases included Alport's disease, analgesic nephropathy, dysplastic kidneys, interstitial nephritis, nephrocalcinosis, nephronophthisis, prune belly syndrome, and von Hippel-Lindau syndrome.

9 There were 9 allograft losses among C3S/S patients who received a C3F/F or C3F/S kidney, and 29 among the C3S/S patients who received a C3S/S kidney.

|| At three months, data on immunosuppressive therapy were available for $83 \mathrm{C} 3 \mathrm{~S} / \mathrm{S}$ patients who received a C3F/F or C3F/S kidney and 112 C3S/S patients who received a C3S/S kidney.

\begin{tabular}{|lccc|}
\hline \multicolumn{4}{|l|}{ Table 2. Multivariate Analysis of Pretransplantation Factors Significantly Affecting Graft Survival.* } \\
\hline \\
Variable & Mean $( \pm \mathrm{SE})$ & Hazard Ratio & \\
C3S/S donor (vs. C3F/S or C3F/F donor), C3S/S recipient & $0.79 \pm 0.40$ & $2.21(1.04-4.72)$ & 0.04 \\
Cadaveric donor (vs. live donor) & $2.79 \pm 1.02$ & $16.30(2.22-119.60)$ & 0.006 \\
\hline
\end{tabular}

* A stepwise stratified Cox model was used. Plus-minus values are means $\pm \mathrm{SE}$. $\mathrm{Cl}$ denotes confidence interval.

a C3S/S recipient. Our data cannot distinguish between these two possibilities.

Our results and the numerous disease associations reported with the $\mathrm{C} 3 \mathrm{~F} / \mathrm{S}$ polymorphism ${ }^{13-16}$ suggest that the two alleles have functional differences. The effect we describe may be due to differential binding of C3F and C3S to C3 receptors. Earlier data suggest that the two alleles vary in their ability to bind complement receptors, ${ }^{29}$ but a later study failed to confirm this result. ${ }^{30}$ The site of the C3F/S polymorphism is away from the known binding sites of complement receptors. However, many of the binding domains on C3 are unknown. This is particularly true for proteins such as CD46 that are not traditionally considered $\mathrm{C} 3$ receptors but that both bind $\mathrm{C} 3$ and possess immunomodulatory activity. ${ }^{31}$ The structure of $\mathrm{C} 3$ has recently been published, ${ }^{32}$ permitting the functional consequences of the C3F/S polymorphism to be predicted. The site of the substitution of glycine (C3F) for arginine (C3S) at position 80 , which results in a change in 


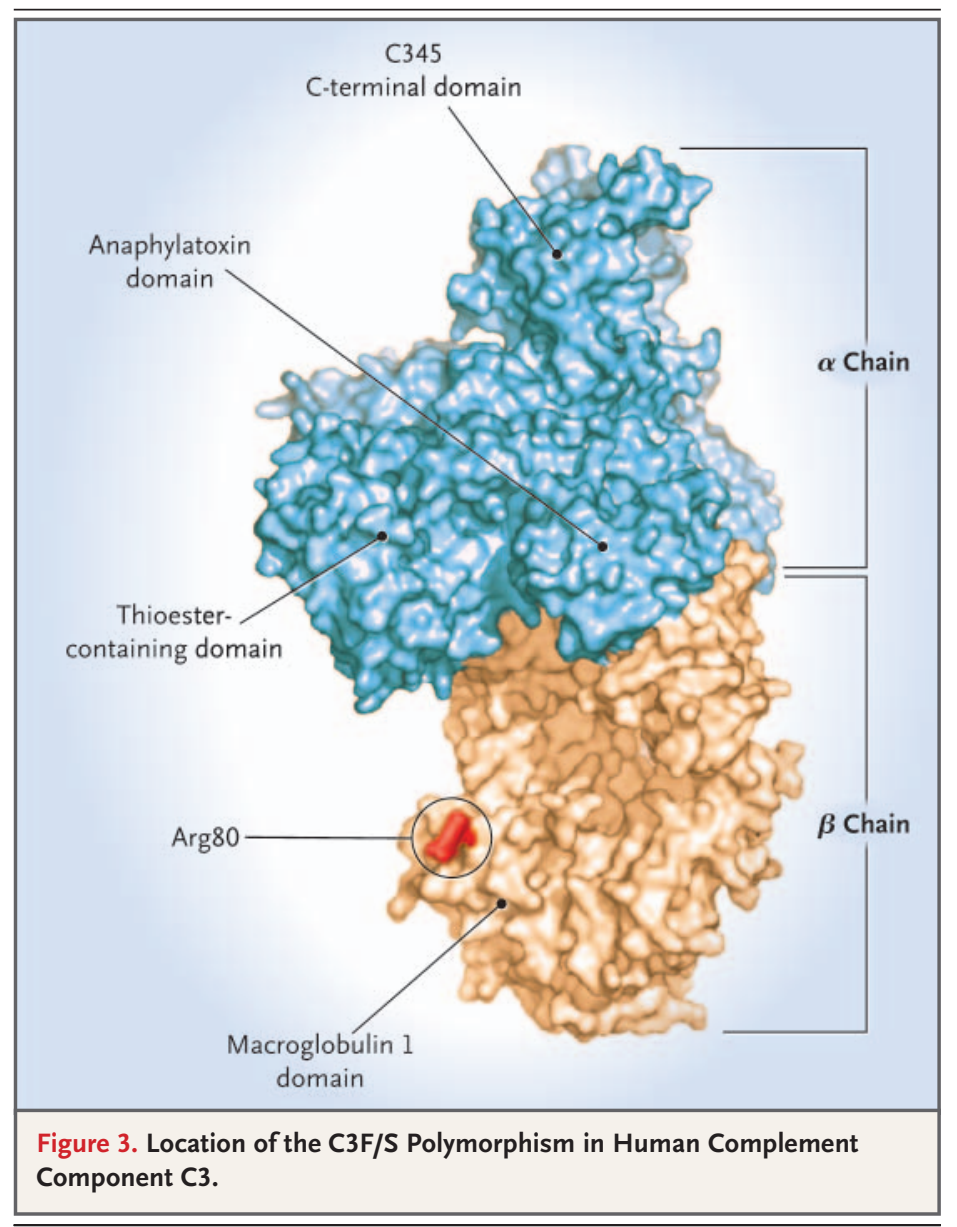

the size and the charge of the amino acid, is on the surface of $\mathrm{C} 3$ and thus may affect interactions with other proteins (Fig. 3).

Alternatively, the $\mathrm{C} 3 \mathrm{~F} / \mathrm{S}$ polymorphism may be linked to a second polymorphism in the coding sequence of the $\mathrm{C} 3$ gene, its promoter region, or other genes in linkage disequilibrium. A second polymorphism in the $\mathrm{C} 3$ gene (HAV4-1) is close to the $\mathrm{C} 3 \mathrm{~F} / \mathrm{S}$ locus, ${ }^{10}$ and there is a strong association between the HAV4-1+ ${ }^{+}$and the C3F alleles. ${ }^{33} \mathrm{~A}$ re- view of chromosome 19p failed to identify other genes that are known to affect transplantation outcome close to the $\mathrm{C} 3$ gene locus. There are several genes of unknown function in this region, and an effect of linkage thus cannot be excluded.

Although previous studies have shown an association between the $\mathrm{C} 3 \mathrm{~F}$ allele and the prevalence of renal diseases, ${ }^{13-16}$ we found that the frequency of $\mathrm{C} 3 \mathrm{~F}$ in donors and recipients was the same as that reported in the general population, which rules out a major effect of the C3F allele in the development of end-stage renal disease.

The concept that polymorphisms within donor kidneys can affect the outcome of transplantation is increasingly acknowledged. Polymorphisms in enzymes that affect the generation of oxygen radicals can affect early graft function. ${ }^{34}$ Hoffmann et al. demonstrated that donor cytokine polymorphisms can affect the likelihood of both acute rejection and, perhaps more strongly, the development of chronic allograft nephropathy. ${ }^{35}$ The main effect of the C3F/S polymorphism in the donor kidney may be on chronic graft injury rather than acute rejection. Studies in other cohorts will be important to define the magnitude of its effect.

Whether these polymorphisms will affect donor-recipient matching is uncertain. However, typing both donor and recipient for these polymorphisms may allow us to identify patients at increased risk for acute or chronic graft dysfunction. This information may allow us to predict outcome more accurately and thus identify highrisk patients who require more intensive surveillance or different immunosuppressive regimens.

Supported by a grant (G0000771, to Dr. Sacks) from the United Kingdom Medical Research Council, a grant (066800-Z-02-2, to Dr. Sheerin) from the Wellcome Trust, and a grant (R011202, to Dr. Sacks) from the Guy's and St. Thomas' Charity.

Dr. Sacks reports having served as a consultant to Adprotec (Inflazyme Pharmaceuticals). No other potential conflict of interest relevant to this article was reported.

\section{REFERENCES}

1. 2004 Annual report of the U.S. Organ Procurement and Transplantation Network and the Scientific Registry of Transplant Recipients: transplant data 1994-2003. Rockville, Md.: Health Resources and Services Administration, Division of Transplantation, 2004.

2. Paul LC. Chronic allograft nephropathy: an update. Kidney Int 1999;56:783-93. 3. Sacks SH, Chowdhury P, Zhou W. Role of the complement system in rejection. Curr Opin Immunol 2003;15:487-92.
4. Walport MJ. Complement: first of two parts. N Engl J Med 2001;344:1058-66.

5. Erdei A, Fust G, Gergely J. The role of C3 in the immune response. Immunol Today 1991;12:332-7.

6. Tang S, Zhou W, Sheerin NS, Vaughan RW, Sacks SH. Contribution of renal secreted complement $\mathrm{C} 3$ to the circulating pool in humans. J Immunol 1999;162: 4336-41.

7. Naughton MA, Botto M, Carter MJ, Alexander GJ, Goldman JM, Walport MJ. Ex- trahepatic secreted complement $\mathrm{C} 3$ contributes to circulating $\mathrm{C} 3$ levels in humans. J Immunol 1996;156:3051-6.

8. Pratt JR, Basheer SA, Sacks SH. Local synthesis of complement component C3 regulates acute renal transplant rejection. Nat Med 2002;8:582-7.

9. Alper CA, Propp RP. Genetic polymorphism of the third component of human complement (C3). J Clin Invest 1968;47: 2181-91.

10. Botto M, Fong KY, So AK, Koch C, Wal- 
port MJ. Molecular basis of polymorphisms of human complement component C3. J Exp Med 1990;172:1011-7.

11. Newton CR, Graham A, Heptinstall LE, et al. Analysis of any point mutation in DNA: the amplification refractory mutation system (ARMS). Nucleic Acids Res 1989;17:2503-16.

12. Poznansky MC, Clissold PM, Lachmann PJ. The difference between human C3F and C3S results from a single amino acid change from an asparagine to an aspartate residue at position 1216 on the alpha-chain of the complement component, C3. J Immunol 1989;143:1254-8.

13. Rambausek M, van den Wall Bake AW Schumacher-Ach R, et al. Genetic polymorphism of $\mathrm{C} 3$ and $\mathrm{Bf}$ in IgA nephropathy. Nephrol Dial Transplant 1987;2:208-11.

14. Finn JE, Zhang L, Agrawal S, Jayne DR, Oliveira DB, Mathieson PW. Molecular analysis of $\mathrm{C} 3$ allotypes in patients with systemic vasculitis. Nephrol Dial Transplant 1994;9:1564-7.

15. McLean RH, Winkelstein JA. Genetically determined variation in the complement system: relationship to disease. J Pediatr 1984;105:179-88.

16. Finn JE, Mathieson PW. Molecular analysis of C3 allotypes in patients with nephritic factor. Clin Exp Immunol 1993;91: 410-4.

17. Andrews PA, Finn JE, Mathieson PW, Sacks SH. Molecular analysis of C3 allotypes related to transplant outcome in human renal allografts. Transplantation 1995 60:1342-6.

18. Afzali B, Shah S, Chowdhury P, O'Sullivan H, Taylor J, Goldsmith D. Low-dose mycophenolate mofetil is an effective and safe treatment to permit phased reduction in calcineurin inhibitors in chronic allograft nephropathy. Transplantation 2005;79: 304-9.

19. Racusen LC, Solez K, Colvin RB, et al. The Banff 97 working classification of renal allograft pathology. Kidney Int 1999; 55 713-23.

20. Bostom AG, Kronenberg F, Ritz E. Predictive performance of renal function equations for patients with chronic kidney disease and normal serum creatinine levels Am Soc Nephrol 2002;13:2140-4.

21. Miller SA, Dykes DD, Polesky HF A simple salting out procedure for extracting DNA from human nucleated cells. Nucleic Acids Res 1988;16:1215.

22. Zhou W, Farrar CA, Abe K, et al. Predominant role for $\mathrm{C} 5 \mathrm{~b}-9$ in renal ischemia reperfusion injury. J Clin Invest 2000;105: 1363-71.

23. Feucht HE, Schneeberger H, Hillebrand $\mathrm{G}$, et al. Capillary deposition of C4d complement fragment and early renal graft loss. Kidney Int 1993;43:1333-8.

24. Sacks SH, Chowdhury P. Footprints of humoral rejection. Curr Opin Nephrol Hypertens 2002;11:627-8.

25. Heeger PS, Lalli PN, Lin F, et al. Decay-accelerating factor modulates induction of T cell immunity. J Exp Med 2005; 201:1523-30.

26. Pratt JR, Abe K, Miyazaki M, Zhou W, Sacks SH. In situ localization of C3 synthesis in experimental acute renal allograft rejection. Am J Pathol 2000;157:825 31.

27. Li K, Patel H, Farrar CA, Hargreaves RE, Sacks SH, Zhou W. Complement activation regulates the capacity of proximal tubular epithelial cell to stimulate alloreactive T cell response. J Am Soc Nephrol 2004;15:2414-22

28. Zhou W, Patel H, Li K, Peng Q, Villiers MB, Sacks SH. Macrophages from C3-deficient mice have impaired potency to stimulate alloreactive T cells. Blood 2006;107: 2461-9.

29. Arvilommi H. Capacity of complement c3 phenotypes to bind on to mononuclear cells in man. Nature 1974;251:740-1.

30. Bartok I, Walport MJ. Comparison of the binding of C3S and C3F to complement receptors types 1, 2, and 3. J Immunol 1995;154:5367-75.

31. Kemper C, Chan AC, Green JM, Brett KA, Murphy KM, Atkinson JP. Activation of human CD4+ cells with CD3 and CD46 induces a T-regulatory cell 1 phenotype. Nature 2003:421:388-92.

32. Janssen BJ, Huizinga EG, Raaijmakers $\mathrm{HC}$, et al. Structures of complement component $\mathrm{C} 3$ provide insights into the function and evolution of immunity. Nature 2005:437:505-11.

33. Koch C, Behrendt N. A novel polymorphism of human complement component C3 detected by means of a monoclonal antibody. Immunogenetics 1986;23:3225.

34. Exner M, Bohmig GA, Schillinger $M$, et al. Donor heme oxygenase-1 genotype is associated with renal allograft function. Transplantation 2004;77:538-42. 35. Hoffmann S, Park J, Jacobson LM, et al. Donor genomics influence graft events: the effect of donor polymorphisms on acute rejection and chronic allograft nephropathy. Kidney Int 2004;66:1686-93.

Copyright 02006 Massachusetts Medical Societp.

FULL TEXT OF ALL JOURNAL ARTICLES ON THE WORLD WIDE WEB Access to the complete text of the Journal on the Internet is free to all subscribers. To use this Web site, subscribers should go to the Journal's home page (www.nejm.org) and register by entering their names and subscriber numbers as they appear on their mailing labels. After this one-time registration, subscribers can use their passwords to log on for electronic access to the entire Journal from any computer that is connected to the Internet. Features include a library of all issues since January 1993 and abstracts since January 1975, a full-text search capacity, and a personal archive for saving articles and search results of interest. All articles can be printed in a format that is virtually identical to that of the typeset pages. Beginning six months after publication, the full text of all Original Articles and Special Articles is available free to nonsubscribers who have completed a brief registration. 